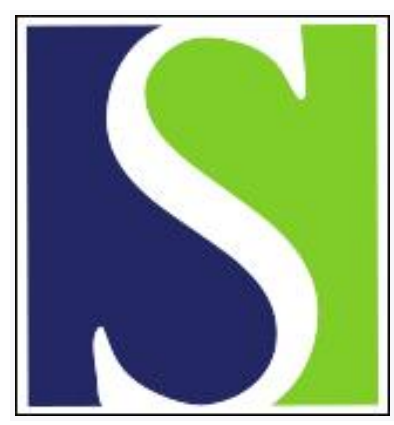

Scand J Work Environ Health 1998;24(6):465-472

https://doi.org/10.5271/sjweh.370

Issue date: Dec 1998

Workplace factors and care seeking for low-back pain among female nursing personnel

by Josephson M, Vingård E, MUSIC-Norrtälje Study Group

The following articles refer to this text: $2001 ; 27(4): 258-267$;

2001;27(6):388-394; 2002;28(6):386-393; 2016;42(6):528-537

Key terms: case-referent study; epidemiology; female; health care; low-back pain; nursing personnel; physical load; psychosocial factor; woman; workplace

This article in PubMed: www.ncbi.nlm.nih.gov/pubmed/9988088 


\title{
Workplace factors and care seeking for low-back pain among female nursing personnel
}

\author{
by Malin Josephson, MSc, ${ }^{1,2}$ Eva Vingård, MD, 1,2,3 MUSIC-Norrtälje Study Group ${ }^{1,2,3,4}$
}

\begin{abstract}
Josephson M, Vingård E, MUSIC-Norrtälje Study Group. Workplace factors and care seeking for lowback pain among female nursing personnel. Scand J Work Environ Health 1998;24(5):465-472.

Objectives Low-back pain is common among nursing personnel, and its origin is multifactorial. The present study focused on physical and psychosocial work load. The objectives of the study were to estimate the relative risk for nursing personnel, compared with other occupational groups, to seek health care for low-back pain, and to identify risk factors.

Methods This study is a part of a population-based case-referent study in the municipality of Norrtälje, situated north of Stockholm. Altogether 333 women served as cases and 733 served as referents. Eightyone cases and 188 referents were employed in nursing work. The cases had sought health care for lowback pain during the study period, November 1993 to November 1996. The referents were randomly selected from the same population. The subjects filled out 2 questionnaires and participated in interviews about physical exposures and psychosocial factors.

Results When the female nursing personnel were compared with other employed women, no increased risk of consultation for low-back pain was found. According to a multivariate logistic regression, nursing personnel exposed to forward-bending working positions, high energetic work load, perceived physical exertion, or insufficient social support had the highest risk estimates. In univariate analyses, the combination of physical and psychosocial risk factors was associated with a particularly high risk.

Conclusions In nursing work, physical load seems to be more significant than psychosocial factors when a worker seeks health care for low-back pain. The results of did not support the hypothesis that nursing work is a risk occupation for seeking care for low-back pain when compared with other occupations.
\end{abstract}

Key terms case-referent study, epidemiology, health care, physical load, psychosocial factors, women

Low-back pain is common among nursing personnel. In a previous study, $53 \%$ of the nurses in a regional hospital reported that they had experienced low-back pain during the previous 12 months, and $16 \%$ reported current intense symptoms in the low-back region (1).

The origin of low-back pain is multifactorial, and the present study focused on workplace factors related to physical and psychosocial load (2, 3). In studies on psychosocial dimensions, physical load is often assessed at the group level (4). In studies on physical factors, the psychosocial conditions have often been ignored or crudely assessed $(5,6)$. When exposures are assessed with different precision, it is difficult to estimate the relative effect of the physical and psychosocial load.

In our study, we assessed physical and psychosocial factors at the individual level. Both interview data with a descriptive focus on the work environment and questionnaire data focused on perceived work load were considered. The objectives of the study were to estimate the relative risk of nursing personnel seeking health care because of low-back pain when compared with other occupational groups and to identify risk factors for health care consultations for low-back pain among nursing personnel.

\footnotetext{
Department for Work and Health, National Institute for Working Life, Solna, Sweden.

Division of Occupational Health, Department Public Health Sciences, Karolinska Institute, Stockholm, Sweden. Department of Occupational Health, Stockholm County Council, Stockholm, Sweden.

National Institute for Psychosocial Factors and Health, Stockholm, Sweden.
}

Reprint requests to: Malin Josephson, Department for Work and Health, National Institute for Working Life, S-171 84 Solna, Sweden. [E-mail: Malin.Josephson@niwl.se] 


\section{Subjects and methods}

This research was a part of the Norrtälje study, a population-based, case-referent investigation of low-back disorders in the municipality of Norrtälje, situated north of Stockholm. The study base comprised about 17000 persons between 20 and 59 years of age, who lived and worked within the municipality. The data collection took place from November 1993 to November 1996. The cases had sought health care from any of the about 70 care givers in the region during the study period. All care givers in the region, such as physicians, physiotherapists, chiropractors, osteopaths, homeopaths and others, took part in the study, and none refused to participate. The referents were selected from the population register as a stratified random sample, taking age (5-year intervals) and gender into account. All the care givers reported patients with low-back problems to the project group. The case patients were contacted by telephone as soon as possible, and a time for the examination was reserved, usually within 1 or 2 weeks and no longer than 2 months after the first contact. The referents were contacted by letter. An inclusion criterion was that the cases and referents should not have sought care for low-back or neck and shoulder pain during the 6 months prior to the study occasion. Altogether 694 cases and 1423 referents, who were gainfully employed at least 18 hours per week for at least 2 months during the previous 12 months, were investigated.

The participation rate for all the formal cases in the study is unknown, but, according to interviews with the care givers, only a few refused to participate. Among the female referents, $31 \%$ could not or did not want to participate; the corresponding frequency was $32 \%$ for the male referents.

The classification as to occupational sectors was based on the Nordic Occupation Classification (7) at the 3-digit level. Nursing occupations included registered nurses, assistant nurses, attendants in psychiatric care, home-care workers, and assistants for the mentally retarded. The registered nurses, the assistant nurses, and the attendants in psychiatric care worked mainly in a hospital setting, in medical, surgical, psychiatric or geriatric wards. The home-care workers were employed by the local municipal authority and worked with elderly people in their private homes. Assistants for the mentally retarded were also employed by the local municipal authority and took care of the mentally retarded in nursing homes. Since there were only 7 male referents and 12 male cases working in nursing occupations, they were excluded from further analysis. In the present study, when self-employed women with occupations requiring at least 6 years of education after compulsory school were excluded, there were 333 women who formed cases and 733 women who acted as referents. Eighty-one of the cases and 188 referents were gainfully employed in nursing work. Of the cases, 1 woman became a case twice according to the inclusion criteria, and 4 referents became cases during the study period.

The subjects took part in a clinical examination, an interview by a physiotherapist about physical exposures, and an interview by a behavioral scientist about psychosocial factors. Furthermore, the participants filled out questionnaires about living conditions, occupational exposure, and general health. The physiotherapist and the behavioral scientist did not know the case-referent status of the subject during the interviews. The assessed exposures and the cut-off points between the exposed and unexposed subjects were determined on the basis of experience, the results of previous studies, knowledge of risk factors and work conditions, and the exposure distribution in the reference group.

\section{Physical factors}

As an overall proxy for the energetic work load, an estimate of the energy expenditure was used. For each task the energy expenditure, expressed as multiples of the resting metabolic rate (MET), was estimated by the physiotherapist. A coding scheme, modified from 2 review articles $(8,9)$, was used for classifying physical activities by rate of energy expenditure. A time-weighted MET (TWA MET) was calculated for a typical workday. A TWA MET of 2.9 or more was the cut-off point for a relatively high energetic load. An energy expenditure of 2.9 MET for an average middle-aged woman represented around $30 \%$ of her maximal aerobic power (10). An upper general limit of around $30-35 \%$ of the maximal aerobic power has been recommended for an 8-hour workday for mixed physical work (11).

A rating of perceived exertion (RPE) was used as an item assessing perceived physical exertion during a normal workday in the questionnaire (12). The RPE scale was set as 6 (resting) to 20 (maximal exertion). Nursing personnel who reported physical exertion higher than "somewhat hard" (score $\geq 14$ ), approximately the highest tertile among the female referents in the Norrtälje study, were categorized as exposed.

Manual lifting of $10 \mathrm{~kg}$ during at least 5 minutes of a typical workday and lifting of at least $30 \mathrm{~kg}$ once a week were considered to be exposure criteria. In addition working in forward-bent positions with the hands below knee level for 1 hour during a typical workday was considered to be high-level exposure; work in the same positions for $1-59$ minutes was regarded as medium exposure.

\section{Psychosocial factors}

The occupational tasks, the duration of each task, and the mental requirements of the work were assessed from the description in the interview. The interviewer calculated 
the time spent in routine work, the active application of knowledge, and problem solving for a typical workday (13). The underlying hypothesis was that work requiring little thinking and planning has negative consequences on health in the long-term (14). "Mainly routine work" was defined as $50 \%$ of the workhours spent in routine work and no tasks requiring problem solving (13).

According to the job-strain model, the combination of high psychological demands, low intellectual discretion, and low authority over decision making was considered to be a job-strain situation and a potential risk factor (15). The index for psychological demands included the following 5 items: excessive work, conflicting demands, time to do work, fast work, and hard work. The score variation was 5 to 20 : the higher the score, the higher the demands. Intellectual discretion included the following 4 items: learning new things, high levels of skill, high levels of creativity, and repetitious job. The score variation was from 4 to 16 : the lower the score, the less the skill discretion. The index of authority over decisions included the 2 items of questions about influence over what to do and how to perform the work. The score variation was 2-8: the lower the score, the less the authority over decisions. The indices were divided into tertiles according to the distribution among the male and female referents in the Norrtalje study. A score of 14--20 for psychological demands, a score of $4-10$ for intellectual discretion, and a score of $2-5$ for authority over decisions were considered potential risk factors. A sum score of 6-16 for low intellectual discretion and authority over decisions (approximately the lowest tertile) combined with high psychological demands (approximately the highest tertile) was categorized as a job-strain situation. The possibilities for social support and satisfying social relations at work were assessed both in the interview (2 questions) and by questionnaire (6 items). The possible score variation was from 8 to 32 : the higher the score, the more satisfied with the social support. A score of 8 to 22 was considered a potential risk factor. The internal consistency of the psychosocial indices was considered acceptable, the Cronbach alpha values were between 0.72 to 0.87 when calculated for the reference nursing personnel $(16,17)$

Terms of employment, living conditions, family situation, and the amount of domestic work were also considered both in the interview and in the questionnaire.

\section{Data analysis}

When nursing personnel with occupations requiring the same level of education were compared, the categorization was based on the Swedish socioeconomic index classification (7). Risk analyses, stratified into 2 age groups by the Mantel-Haenszel method, and a logistic regression analysis were conducted. In the logistic regression factors with an odds ratio (OR) of 1.5 or greater in the

univariate analysis were included, along with age and smoking. The stability of the logistic regression analysis was tested by the Hosmer \& Lemeshow test (18). The highest correlated exposure variables included in the multivariate analysis were workhours/week and nightshift work (Spearman rank correlation coefficient of -0.37 ). In the multivariate analysis all the variables were dichotomized except age, which was treated as a continuous variable. In the Norrtälje study the data were frequency-matched for age to increase the efficiency of the study. In the analyses, age was considered to be a potential confounder or effect modifier (19).

\section{Results}

The majority of the nursing personnel was always or almost always satisfied with the support from their workmates and supervisors, and only 6 reported mainly routine work and no problem solving. The median number of workhours per week was 34 for the referents in nursing work and 30 for the cases in nursing work. Part-time (15-29 hours/week) work was associated with night shifts. Seventy-seven percent of the referents and 93\% of the cases on night shift were employed part-time.

A comparison of nursing personnel with the other occupational groups did not show any increased risk of consultation for low-back pain (table 1). On the contrary, the risk was lower for the registered nurses than for the other employed women in occupations requiring the same level of education (table 1).

High energetic work load, work in forward-bent positions, low intellectual discretion, low authority over decisions, part-time work, temporary employment, and night shifts were less frequent among the registered nurses than among the other nursing groups (table 2).

Table 1. Risk estimates for seeking care for low-back problems for female nursing personnel in a comparison with employed women not working as nurses but in occupations requiring the same level of education. In the analysis the subjects were stratified into 2 age groups ( $<45$ years, $\geq 45$ years), and risk estimates were calculated by the Mantel-Haenszel method.

\begin{tabular}{|c|c|c|c|c|c|c|}
\hline \multirow[t]{2}{*}{$\begin{array}{l}\text { Different catego- } \\
\text { ries of nursing } \\
\text { personnel } \\
\text { (potential risk } \\
\text { of exposure) }\end{array}$} & \multicolumn{2}{|c|}{$\begin{array}{l}\text { Nursing } \\
\text { personnel } \\
\text { ("exposed } \\
\text { groups") }\end{array}$} & \multicolumn{2}{|c|}{$\begin{array}{l}\text { Employed } \\
\text { women not } \\
\text { working as } \\
\text { nurses (com- } \\
\text { parison group) }\end{array}$} & \multirow[t]{2}{*}{ OR } & \multirow[t]{2}{*}{$95 \% \mathrm{Cl}$} \\
\hline & Cases & Referents & Cases & Referents & & \\
\hline Registered nurses & 3 & 41 & 79 & 204 & 0.2 & $0.1-0.5$ \\
\hline $\begin{array}{l}\text { Assistant nurses, } \\
\text { attendants in } \\
\text { psychiatric care }\end{array}$ & 30 & 67 & 69 & 146 & 1.0 & $0.6-1.6$ \\
\hline $\begin{array}{l}\text { Home-care workers } \\
\text { and assistants for } \\
\text { the mentally retarded }\end{array}$ & 48 & 80 & 104 & 195 & 1.1 & $0.7--1.8$ \\
\hline
\end{tabular}


Table 2. Distribution of exposure factors among the referents. The differences between the registered nurses and the other nursing personnel (assistant nurses, attendants in psychiatric care, home-care workers and assistants for the mentally retarded) in proportion exposed (proportion of exposed registered nurses minus proportion of other exposed nursing personnel) and $95 \%$ confidence intervals $(95 \% \mathrm{Cl})$ of the differences.

\begin{tabular}{lcccc}
\hline Exposure & Regis- & Dther & Differ- & $95 \% \mathrm{Cl}$ \\
factors & tered & nursing & ences in & \\
& nurses & person- & propor- & \\
& $(\%)$ & nel $(\%)$ & tion $(\%)$ &
\end{tabular}

\section{Working in}

forward-bent

positions

Heavy manual liftinga

(weekly)

Manual lifting (daily)

High energetic work

load

High perceived physical

exertion

High psychological

demands

Low intellectual

discretion

Low authority over

decisions

Job strain

Insufficient social

support

Mainly routine work

Part-time work

Night shifts

Temporary employment

Current smoking

\begin{tabular}{rrrr}
66 & 86 & -20 & $-36--5$ \\
27 & 18 & 9 & $6-24$ \\
7 & 13 & -6 & $-4-15$ \\
0 & 16 & -16 & $-22--10$ \\
18 & 32 & -14 & $-29-0$ \\
41 & 20 & 21 & $5-38$ \\
7 & 39 & -32 & $-44--25$ \\
74 & 39 & -15 & $-30-0$ \\
0 & 8 & -8 & $-13--3$ \\
12 & 7 & 5 & $-6-16$ \\
0 & 3 & -3 & $-6-0$ \\
10 & 33 & -23 & $-35--12$ \\
7 & 13 & -6 & $-15-4$ \\
5 & 24 & -19 & $-28--9$ \\
12 & 31 & -19 & $-31--6$ \\
\hline
\end{tabular}

$\geq 30 \mathrm{~kg}$ at least once a week.

$0 \geq 10 \mathrm{~kg}$ at least 5 minutes/day.

However, high psychological demands were more frequent among the registered nurses (table 2). The assistant nurses, attendants in psychiatric care, home-care workers, and assistants for the mentally retarded were compared with the registered nurses, and the risk estimate for seeking care for low-back disorders was 7.2 (95\% CI $2.5-21)$.

The highest risk estimate for the nursing personnel was found for those highly exposed to work in forwardbent positions (table 3 ). Except for low intellectual discretion, the increased relative risk estimates for different exposure factors in the univariate analyses were confirmed in the multivariate analysis (table 3 ).

Living conditions, current smoking, and age were not associated with an increased estimated relative risk (table 3). Of the psychosocial factors, insufficient social support was associated with the highest relative risks (table 3). In the univariate analyses, combined exposure to forward-bent work positions and low intellectual discretion gave an increased risk estimate of 9.0 (95\% CI $2.5-$ 33). Nursing personnel with insufficient social support in combination with forward-bent work positions had a risk estimate of 6.2 (95\% CI 1.7-22). However, no multiplicative interaction effects of the included variables were observed in the multivariate analysis.

\section{Discussion}

In this study, nursing work, especially work as a registered nurse, seemed to decrease the relative risk of consultation for low-back pain. An increased prevalence of low-back pain has been reported for nursing personnel in a comparison with the general population (20). Official Swedish statistics for 1995-1996 show an increased prevalence of low-back pain for assistant nurses and home-care workers when compared with that of the general working population, whereas no difference appears between registered nurses and the general working population (21). Presumably, the relatively low-risk level for registered nurses can partly be explained by a low physical work load. According to previous studies, assistant nurses have a higher physical work load and also a greater risk of low-back pain when compared with registered nurses $(22,23)$.

Work in forward-bent positions and with a high energetic load, but without lifting, was associated with an increased relative risk in our study. Several studies on nursing personnel have shown an association between the amount of patient-handling and the risk of low-back pain (24). Patient-handling involves work in forward-bent positions, lifting, and also manual handling such as pushing and pulling. In the present analyses pushing and pulling were not considered, and it could be that energetic load and the time spent in bent positions were better estimates than lifting for the time in patient-handling.

If the observed association between work in bent positions and consultation for low-back pain is causal, an attributable fraction can be calculated [(RR-1/RR) $\times$ proportion of cases exposed] (19). The attributable fraction can be explained as the proportion of cases whose disorder was caused by the examined exposure. If work in forward-bent positions is not considered part of the work load, $73 \%$ of the cases of consultation for low-back pain could have been prevented in our study.

A high RPE was associated with an increased relative risk in our study. In previous studies, ratings on the RPE scale have been useful for listing the patient-handling tasks perceived as most stressful for the low back (25). In our study the RPE scale was used as an item in a questionnaire, and the instructions to the subjects were to report the perceived physical exertion in their daily work. In accordance with previous studies, the variation in the RPE not only seemed to mirror the physical activity, but maybe also the worker's physical capacity and the psychological load $(26,27)$. If the RPE scale is used 
Table 3. Number of exposed subjects among the referents and cases. The estimated odds ratios (OR) with $95 \%$ confidence intervals $(95 \% \mathrm{Cl})$, adjusted for age by the Mantel-Haenszel method, and the estimated OR in a multiple invariate logistic regression analysis. In the logistic regression, besides age and smoking, factors with a crude risk estimate of $\geq 1.5$ were included. (Intercept -4.5 , log likelihood $=280.998$, Hosmer \& Lemeshow goodness-of-fit test P-value $=0.13$ ). Age was examined as a potential confounder.

\begin{tabular}{|c|c|c|c|c|c|c|c|}
\hline Exposure factors & $\begin{array}{l}\text { Exposed } \\
\text { referents }\end{array}$ & $\begin{array}{l}\text { Exposed } \\
\text { cases }\end{array}$ & $\begin{array}{l}\text { Age-adjusted } \\
\mathrm{OR}^{\mathrm{a}}\end{array}$ & $95 \% \mathrm{Cl}^{\mathrm{b}}$ & $\begin{array}{l}\text { OR in multivariate } \\
\text { logistic regression }\end{array}$ & $95 \% \mathrm{Cl}^{\mathrm{G}}$ & Missing \\
\hline Working in forward-bent positions & 154 & 77 & 4.3 & $1.6-12$ & & & 1 \\
\hline $\begin{array}{l}\geq 60 \text { minutes per day } \\
1-59 \text { minutes per day }\end{array}$ & $\begin{array}{r}15 \\
139\end{array}$ & $\begin{array}{l}17 \\
60\end{array}$ & 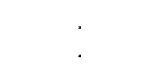 & & $\begin{array}{l}8.7 \\
2.2\end{array}$ & $\begin{array}{l}2.1-46 \\
0.7-10\end{array}$ & . \\
\hline \multicolumn{8}{|l|}{ Manual lifting } \\
\hline $\begin{array}{l}\geq 30 \mathrm{~kg} \text { at least once a week (compared } \\
\text { with }<10 \mathrm{~kg} \text { ) } \\
\geq 10 \mathrm{~kg} \text { at least } 5 \text { minutes per day }\end{array}$ & $\begin{array}{l}37 \\
22\end{array}$ & $\begin{array}{l}16 \\
11\end{array}$ & $\begin{array}{l}1.1 \\
1.2\end{array}$ & $\begin{array}{l}0.5-2.2 \\
0.6-2.6\end{array}$ & . & & $\begin{array}{r}2^{d} \\
3\end{array}$ \\
\hline High energetic work load & 23 & 18 & 2.1 & $1.1-4.2$ & 2.3 & $1.0-5.3$ & 1 \\
\hline High perceived physical exertion & 51 & 40 & 2.7 & $1.6-4.7$ & 2.3 & $1.2-4.5$ & 15 \\
\hline High psychological demands & 46 & 12 & 0.5 & $0.3-1.0$ & . & & 12 \\
\hline Low intellectual discretion & 61 & 40 & 2.0 & $1.2-3.4$ & 1.2 & $0.6-2.2$ & 11 \\
\hline Low authority over decisions & 69 & 30 & 1.1 & $0.6-1.9$ & . & & 8 \\
\hline Job strain & 12 & 6 & 1.2 & $0.4-3.3$ & . & & 20 \\
\hline Insufficient social support & $\$ 1$ & 16 & 1.7 & $0.8-3.8$ & 2.4 & $0.9-6.4$ & 18 \\
\hline Mainly routine work & 5 & 1 & 0.4 & $0.1-3.2$ & . & & 2 \\
\hline Temporary employment & 37 & 21 & 1.9 & $0.9-4.2$ & 1.6 & $0.7-3.4$ & 3 \\
\hline Part-time work & 53 & 35 & 2.0 & $1.1-3.4$ & 1.6 & $0.8-3.5$ & \\
\hline Night shifts & 22 & 15 & 1.7 & $0.8-3.4$ & 1.5 & $0.5-4.4$ & 4 \\
\hline \multicolumn{8}{|l|}{ Children } \\
\hline $\begin{array}{l}0-6 \text { years at home } \\
0-8 \text { years at home }\end{array}$ & $\begin{array}{l}40 \\
67\end{array}$ & $\begin{array}{l}11 \\
18\end{array}$ & $\begin{array}{l}0.6 \\
0.5\end{array}$ & $\begin{array}{l}0.3-1.4 \\
0.3-1.0\end{array}$ & . & & - \\
\hline Single parent & 15 & 4 & 0.6 & $0.2-1.9$ & . & & 1 \\
\hline Responsible for daily domestic work & 134 & 59 & 1.1 & $0.6-2.0$ & . & & 3 \\
\hline Domestic work $\geq 5$ hours per day & 34 & 17 & 1.1 & $0.6-2.1$ & . & & - \\
\hline Current smoking & 50 & 24 & 1.2 & $0.6-2.0$ & 1.0 & $0.5-1.9$ & - \\
\hline
\end{tabular}

${ }^{\circ} \mathrm{OR}$ adjusted for age ( $<45, \geq 45$ years) by the Mantel-Haenszel method.

- For the age-adjusted $O R$.

- For the $O R$ in the multivariate logistic regression.

d 92 subjects lifted $10-20 \mathrm{~kg}$ at least once a week.

as an item in a questionnaire to identify those with a high physical load, the extent of independent misclassification may be substantial.

In a previous study among nursing aides in geriatric care, the cross-sectional analysis and the 6-month followup demonstrated a weak tendency towards a higher prevalence of low-back pain among the persons who reported a high level of physical exertion at work (27). In another study, including 4 annual cross-sectional surveys in a hospital setting, a higher prevalence of symptoms from the neck, shoulders, and back was observed among the persons who reported high physical exertion. In the 1-, 2-, and 3-year follow-up analyses the crude point estimate of the risk ratio for having current symptoms was between 1.3 and 1.6 for the high-exertion group (1). Perceived high physical exertion in nursing work may partly be an effect of current low-back pain, but our study and previous studies indicate that high perceived physical exertion is a risk indicator of a condition preceding low-back pain.

Insufficient social support is strenuous in itself and may probably also increase the negative effect of other strenuous work conditions (28). Studies concerning the influence of social support on low-back pain are not consistent. One showed that nursing personnel who reported low-back pain were more satisfied in their relationship with workmates (29). In a Swedish study among nursing personnel low support from superiors was related to low-back pain (22), while, in another study (30), low support was related to neck and shoulder symptoms but not with symptoms from the low back. In a study concerning home-care workers, social support had no main effect on low-back symptoms, but it modified the effect of physical and psychological work load (31). Our study indicated evidence for a direct association between insufficient social support and low-back pain. However, the frequency of insufficient social support was low and the association was not significant.

Job strain was less frequent among the registered nurses than among the women in the nursing occupations with a relatively increased risk of low-back pain. On the other hand, in the analyses on the individual level, when nursing personnel who reported job strain were compared with nursing personnel not reporting job strain, no increased relative risk was shown. In 1 study, including 4 annual cross-sectional surveys in a hospital setting, the 
risk ratio for current symptoms from the neck, shoulders, or back was between 1.1 and 1.5 for the job strain group when compared with that of the other members of the nursing staff (1). In 2 cross-sectional studies among nursing personnel, a significant relationship between job strain and low-back pain was observed $(5,30)$. In our study the outcome definition was incident cases of care sought for low-back pain, whereas in the studies with a positive relationship, the outcome was the prevalence of self-reported symptoms. The prevalence of self-reported low-back pain is dependent both on the incidence and the duration of the symptoms, and job strain may be more relevant for the duration of symptoms than for the onset of low-back pain.

Working part-time seemed to imply an increased risk for low-back pain. In a previous cross-sectional study on female hospital staff, full-time and part-time workers did not differ in the prevalence of low-back pain. However, a multiple analysis indicated that psychosocial job factors were associated with the intensity of low-back pain for full-time workers but not for part-time personnel (32). In order to test the same hypothesis, we stratified the univariate analyses for workhours, but no differences in risk were observed.

Our study indicated a positive relationship between night shifts and low-back pain and supported the hypothesis of an independent association between night shifts and low-back pain. Night shifts had been shown to be connected with reduced sleeping time, and, in addition, subjective sleep quality is reduced (33). One hypothesis is that sleep disturbance leads to increased muscle tension that contributes to pain in the low back (34).

Forward-bent positions in combination with strenuous psychosocial conditions or night shifts increased the estimate for low-back pain. Different explanations have been suggested for a combined effect of psychosocial and physical risk factors. Increased muscle tension due to strenuous psychosocial conditions may lead to increased vulnerability to physical demands (34). Furthermore, low control in the planning of patient-handling tasks may lead to unsuitable and strenuous work positions $(4,34-36)$. However, in the risk calculations of the effects of the combination of potential risk factors compared with no exposure, the statistical power became low since few cases were exposed to a potential physical or psychosocial risk factor. It was not possible to estimate reliably whether the combination of risk factors exceeded their additive effect.

Our study focused on risk factors for health care consultations for low-back problems and did not include the actual presence of disorders, symptoms, and pain from the low back. In previous studies concerning low-back pain and work factors the definitions of disorders have not been consistent. Pain, pain leading to incapacity, sickness absence, incapacity for daily tasks, the duration of pain, the intensity of the pain, and back problems at the workplace are examples of outcome definitions (3). In our study health-care seeking was used as a proxy for the incidence of low-back disorders. All the subjects were examined by a physiotherapist according to a standardized procedure. The cases were classified into a group with clinical signs of low -back pain or sciatica and a group without any objective clinical signs. Of the health care personnel, 47 of 81 cases had objective signs and a diagnosis. The risk estimates did not vary a great deal between the cases with and without diagnosis.

One conceivable selection bias for this study could be that health care personnel, especially registered nurses, do not seek care for their pain. However, among the female referents, $34 \%$ reported current low-back pain. Of the registered nurses $22 \%$ of the referents reported current pain, the corresponding figures being $32 \%$ for the assistant nurses and $38 \%$ for the home-care workers. The data did not support the hypothesis that health-care personnel suffer from low-back disorders without seeking care to a greater extent than do other employed women.

On the contrary, one possible selection bias could be that nursing personnel seek medical treatment for disorders more often than do other occupational groups (37). Nursing personnel possibly rely more on professional care than women employed outside the health-care sector. An inclusion criterion of this study was that the cases and the referents should not have sought care for lowback and neck or shoulder pain during the 6 months prior to the study occasion. Chronic cases currently under treatment for low-back pain were excluded. Thus a possible referral bias was that nursing personnel were currently under treatment more often than the other occupational groups.

A possible cause of the low risk for registered nurses when compared with that of the other groups could be that the health care sector in Nortälje was better supplied with transfer equipment or that the patients' requirements for care involved less load than in other regions in Sweden. None of the official statistical data, interviews with employees, or visits to workplaces supported this explanation.

The physical and psychosocial work factors were not assessed independently of the person in that the assessments were based on interviews and questionnaires. Differential recall bias is a validity problem in case-referent studies. It is possible that low-back pain biases the selfassessment of the work load. If the cases recalled the exposure with better accuracy or exaggerated the exposure when compared with the referents, it led to an overestimation of the observed risk factors. In the analyses, the individual reporting and the exposure distribution at the occupational level were considered. Differences between the registered nurses and the other nursing occupations in the proportions exposed in the reference group, the risk 
of seeking care for low-back pain in different occupational groups, and the risk factors at the individual level were presented. When the exposure pattern among the referents is considered, potential recall bias due to lowback disorders is reduced. Furthermore, when the reporting of exposure at the occupational level is examined, the importance of individual biasing factors decreases. On the other hand, exposure assessments based on occupation ignore differences in work conditions for different persons in the same occupation (38).

Perceived physical load and psychosocial factors, re-. ported in the questionnaires, reflected the work conditions but were probably also associated with the person's psychological and physical status and factors outside work. The interview methods were developed on the basis of the statement that an interview gives more descriptive information than self-reported questionnaires (13, 39).

\section{Acknowledgments}

This study was supported by grants from the Swedish Council For Work Life Research. We would also like to thank the project coordinator Marianne Ekdahl, physiotherapists Agneta Bergqvist, Kerstin Fredriksson, Ola Leijon, Monica Mortimer, Gunilla Pernold and Christina Wiktorin, and behavioral scientists Gunnel AhlbergHultén, Kerstin Johansson, Cathrine Persson, Eija Viitasara and Måns Waldenström.

\section{References}

1. Josephson M, Lagerström M, Hagberg M, Wigaeus Hjelm E. Musculoskeletal symptoms and job strain among nursing personnel: a study over a three-year period. Occup Environ Med 1997;54:681-5.

2. Riihimäki H. Low-back pain, its origin and risk indicators [editorial]. Scand Work Environ Health 1991;17:81--90.

3. Frank JW, Kerr MS, Brooker A-S, DeMaio SE, Maetzel A, Shannon HS, et al. Disability resulting from occupational low back pain, part 1: what do we know about primary prevention? a review of the scientific evidence on prevention before disability begins. Spine 1996;21:2908-17.

4. National Institute for Occupational Safety and Health (NIOSH). Work-related musculoskeletal disorders and psychosocial factors. In: Bernard B, editor. Musculoskeletal disorders and workplace factors. Cincinnati $(\mathrm{OH})$ : US Department of Health and Human Services (NIOSH), 1997: chapter 7. Publication no 97-141.

5. Jensen R. Back injuries among nursing personnel related to exposure. Appl Occup Environ Hyg 1990;5:38--45.

6. Smedley J, Egger P, Cooper C, Coggon D. Manual handling activities and risk of low back pain in nurses. Occup Environ Med 1995;52:160-3.
7. Statistics Sweden. Population and housing census 1990. Stockholm: Statistics Sweden, 1992.

8. Ainsworth BE, Haskell WL, Leon AS, Jacobs JR, Montoye HJ, Sallis JF, et al. Compendium of physical activities: classification of energy costs of human physical activities. Med Sci Sports Exerc 1993;25:71—80.

9. Mälkiä E, Impivaara O, Maatela J, Aromaa A, Heliövaara M, Knekt P. Physical activity of Finnish adults. Turku (Finland): Social Insurance Institution, 1988;80:55-98.

10. Åstrand PO, Rodahl K. Textbook of work physiology physiological bases of exercises. Singapore: McGraw-Hill Book Co, 1986.

11. Jörgensen K. Permissible loads based on energy expenditure measurements. Ergonomics 1985;28:365--9.

12. Borg G. Psychophysical scaling with applications in physical work and the perception of exertion. Scand J Work Environ Health 1990;16 suppl 1:55--8.

13. Waldenström $\mathrm{M}$, Josephson $\mathrm{M}$, Persson $\mathrm{C}$, Theorell $\mathrm{T}$. Interview reliability for assessing mental work demands. J Occup Health Psychol. In press.

14. Volpert W, Kötter W, Gohde H-E, Weber WG. Psychological evaluation and design of work tasks: two examples. Ergonomics 1989;32:881-90.

15. Karasek RA, Theorell T. Healthy work. New York (NY): Basic Books, 1990.

16. Cronbach LJ. Coefficient alpha and the internal structure of tests. Psychometrika 1951;16:297-34.

17. Theorell T. On the psychosocial environment in care. In: Hagberg M, Hofmann F, Stoesel U, Westlander G, editors. Occupational health for health care workers international congress on occupational health. Freiburg (Germany): Ecomed, 1992:387-93.

18. Hosmer DW, Lemeshow S. Applied logistic regression. New York (NY): John Wiley \& Sons, 1989.

19. Rothman KJ. Modern epidemiology. Boston (MA): Little, Brown and Company, 1986.

20. Pheasant $S$, Stubbs D. Back pain in nurses: epidemiology and risk assessment. Appl Ergon 1992;23:226-32.

21. The National Board of Occupational Safety and Health, Statistics Sweden. När kroppen tar stryk [When the body is hurt]. Stockholm: The National Board of Occupational Safety, 1997. English summary.

22. Lagerström M, Wenemark M, Hagberg M, Wigaeus Hjelm E, the MOSES study group. Occupational and individual factors related to musculoskeletal symptoms in five body regions among Swedish nursing personnel. Int Arch Occup Environ Health 1995:68:27-35.

23. Videman T, Nurminen T, Tola S, Kourinka I, Vanharanta $H$, Troup JDG. Low-back pain in nurses and some loading factors of work. Spine 1984;9:400-4.

24. Hignett S. Work-related back pain in nurses. J Adv Nurs 1996;23:1238-46.

25. Garg A, Owen BD, Carlson B. An ergonomic evaluation of nursing assistants' job in a nursing home. Ergonomics 1992;35:979-95.

26. Wigaens Hjelm E, Winkel J, Nygård C-H, Wiktorin C, Karlqvist L, Stockholm MUSIC 1 Study Group. Can cardiovascular load in ergonomic epidemiology be estimated by selfreport? J Occup Environ Med 1995;37:1210-17.

27. Josephson M, Hagberg M, Wigaeus Hjelm E. Self-reported physical exertion in geriatric care - a risk indicator for low back symptoms? Spine 1996;21:2781-5.

28. Büssing A. A dynamic view of job satisfaction in psychiatric nurses in Germany. Work Stress 1992;6:239_59. 
29. Skovron ML, Mulvihill MN, Sterling R, Nordin M, Tougas $\mathrm{G}$, Gallagher $\mathrm{M}$, et al. Work organization and low back pain in nursing personnel. Ergonomics 1987;30:359-66.

30. Ahlberg-Hultén G, Theorell T, Sigala F. Social support, job strain and musculoskeletal pain among female health care personnel. Scand J Work Environ Health 1995;21:435-9.

31. Johansson $\mathrm{J} \AA$. Psychosocial work factors, physical work load and associated musculoskeletal symptoms among home care workers. Scand J Psychol 1994;36:113-29.

32. Bru E, Mykletun RJ, Svebak S. Work-related stress and musculoskeletal pain among female hospital staff. Work Stress 1996;10:309-21.

33. Kecklund G. Sleep and alertness: effects of shift work, early rising, and the sleep environment. Stockholm: Karolinska Institute, 1996:94 p.

34. Theorell T, Harms-Ringdahl K, Ahlberg-Hultén G, Westin B. Psychosocial job factors and symptoms from the locomotor system - a multicausal analysis. Scand J Rehabil Med 1991;23:165-73
35. Bongers PM, de Winter CR, Kompier MAJ, Hildebrant VH. Psychosocial factors at work and musculoskeletal disease. Scand J Work Environ Health 1993;19:297-312.

36. Nordin M, Andersson G, Pope M. Musculoskeletal disorders in the workplace: principles and practice. St Louis (MO): Mosby, 1997.

37. Tüchsen F, Andersen O, Olsen J. Referral bias among health workers in studies using hospitalization as a proxy measure of the underlying incidence rate. J Clin Epidemiol 1996;49:791-4.

38. Burdorf A. Exposure assessment of risk factors for disorders of the back in occupational epidemiology [review]. Scand J Work Environ Health 1992;18:1 — 9 .

39. Wiktorin C, Karlquist L, Winkel J, Stockholm MUSIC 1 Study Group. Validity of self-reported exposures to work postures and manual materials handling. Scand $\mathbf{J}$ Work Environ Health 1993;19:208-14.

Received for publication: 23 January 1998 